\title{
An Empirical Analysis of Interrelationship between Income, Health and Entrepreneurship
}

\author{
Shen Shen ${ }^{1}$, Hexin Wang ${ }^{1}$, Xin Shi ${ }^{2}$ \\ ${ }^{1}$ School of Economics and Management Department, Beihang University, Beijing, China \\ ${ }^{2}$ Business School, Manchester Metropolitan University, Manchester, UK \\ Email: shenshenbh@gmail.com, wanghexin@buaa.edu.cn, x.shi@mmu.ac.uk
}

Received 2012

\begin{abstract}
This study uses a longitudinal data set from 1991 to 2008 to investigate the relationship between income, health and entrepreneurship in the long term. Different from previous research based on cross-sectional data, our study finds that the self-employed do not have an advantage in earnings over the employee, and the interrelation between income and entrepreneurship is rather small in the long run. This is because incomes of the employee grow steadily over the years while those of the self-employed fluctuate almost around a constant level. Moreover, the self-employed are in association with better subjective well-being but worse objective health condition than the employee, largely because of the work characteristics of the two employment options. However, the self-employed tend to visit hospital less than the employee in spite of their poorer physical health. Based on the principal findings in this study, we provide some valuable policy suggestions aimed at promoting entrepreneurship.
\end{abstract}

Keywords: Entrepreneurship; Income; Health; Longitudinal Data

\section{Introduction}

Entrepreneurship has drawn more attentions from the policymakers in recent years, due to constantly low employment rate since the latest economic crisis. In 2011, British government successively launched two programmes to provide financial support and mentor support for people who want to start and grow their own businesses. As an alternative to paid-employment, entrepreneurship could help individuals out of unemployment status and simultaneously create extra job opportunities in labor market. Other main advantages of entrepreneurship include: the feeling of achievement, high degree of independence and potential for greater financial returns [1]. However, the self-employed always have to put more effort and time into their businesses, and thus experience more health problems [2]. This study aims to investigate the relationship between income, health and personal choice between entrepreneurship and paid-employment in Britain, and provide some policy implications for policymakers.

Rees and Shan (1986) are among the earliest to analyze the relationship between employment status and earnings, using an econometric model. And they found that, the probability of entrepreneurship increases in earnings differential between entrepreneurship and paid-employment [3]. Later researches gained the same result and considered the higher income as one of important attraction of entrepreneurship [4] [5]. However, there are also some researchers who provided different insight. Blanchflower and Shadforth (2007) pointed out that, the self-employed have actually lower median income than the employee, and nonpecuniary benefits, such as job satisfaction, are the main reasons individual chooses entrepreneurship [6]. The relationship between health and entrepreneurship has also been discussed in previous research. Jamal (2007) indicated the self-employed are positively associated with overall burnout, largely because entrepreneurship is more demanding for personal energy [7]. Lewin-Epstein and Yuchtman-Yaar (1991) found the self-employed have greater risks in their lifestyle and suffer from more health problems than the employee [8]. Besides, there are other studies which highlight the poorer mental health among the self-employed, due to the higher job stress [9] [10].

Generally, this study has two main differences from previous research. First, former papers often base their analysis of entrepreneurship on cross-sectional data. However, it is more appropriate to build up a life course model by using longitudinal data, to reflect the long-term impact of various factors on entrepreneurship [11]. In light of this insight, our study chooses to use a data sample across 18 years to trace the dynamic process of individuals in various socio-economic respects. Second, 
there is little previous research into how income, health and entrepreneurship are correlated to each other. Nowadays, fewer and fewer people are willing to earn higher income at the cost of health status. So it is strategically important to look into this issue.

The rest of this paper is organized as follows. Section 2 introduces the general profile of our data sample and the methods we use to impute and model the longitudinal data. In section 3 and 4, we conduct descriptive statistics and model analysis respectively, to reveal the interrelationship between income, health and the entrepreneurship. In section 5 , we put forward some suggestions on how to promote the entrepreneurship based on the results before. Section 6 draws conclusion and provides some directions of further extensions.

\section{Methodology}

In this section, we firstly present the profile of our data sample that is used for our analysis, and explain how we imputed the missing data in the sample. Then we introduce the statistical approach we applied to handle the longitudinal data in our research.

\subsection{Data Sample and Imputation}

We use data from BHPS (British Household Panel Survey), which is designed as an annual survey since 1991 of each adult member of a nationally representative sample of more than 5,000 households, making a total of approximately 10,000 individual interviews. In order to reflect the long-term relationship between income, health and self-employment, our sample contains data from 1991 to 2008. Moreover, 67 variables are selected from BHPS for future modeling. Specifically, we employ the subject's employment status as the dependent variable, which measures the choice between entrepreneurship and paid-employment. And our dependent variables incorporate income variables, health variables and other variables, which are included to control for the differences between the self-employed and the employee in other respects.

Then we discuss the methods used to impute the missing data. First, we only reserve the complete cases for the dependent variables. It means any respondent who fails to answer his/her employment status in any year is deleted. Second, missing data on income variables have been imputed in all years by BHPS. Finally, we use LOCF (Last Observation Carried Forward) and NOCB (Next Observation Carried Backward) to deal with missing data on other variables. For each respondent, LOCF use the last observed value of that variable to replace the missing value, while NOCB use the next observation. This two imputation techniques are not ex- pected to bring bias into our statistical analysis, because the missing data rate is between 0 and $2 \%$ on every variable in our data set [12].

\subsection{Modeling Approach}

Different from cross-sectional data, longitudinal data set contains repeated observed values on the same variable for each subject across years. It is necessary to account for the correlation between the repeated observations in order to obtain a correct statistical result. Besides, a great deal of modeling approach only applies to the analysis when the dependent variable is approximately Gaussian. But our dependent variable, the choice between entrepreneurship and paid-employment, is binary nominal variable and thus non-Gaussian.

However, the GEE (Generalized Estimating Equations) approach could deal with the above two problems [13]. First, GEE introduces a "working " correlation matrix to cope with the interrelationship between observed values within each subject across years. And it is noted that, this matrix is not expected to be correctly specified to obtain the consistent estimators. Second, the GEE is developed from quasi-likelihood theory, which requires few requirement about the distribution of dependent variable. So the GEE is able to handle a great deal of distribution, including binary variable.

For model section, we employ the QIC (Quasi-likelihood Information Criterion), which is a modification to AIC (Akaike Information Criterion) to be the effective criteria available for GEE [14]. And the best GEE model is the one with the smallest value in QIC.

\section{Descriptive Statistics}

Longitudinal data set from 1991 to 2008 is derived from BHPS. We excluded the respondents with missing data on the dependent variable, that is the employment status, in any years. Finally, 1303 respondents are left in our data set, and self-employment rate of our sample is between $11 \%$ and $16 \%$ over the 18 years.

We employ the monthly net payment to measure the income level. It is noted that, incomes of all years are in real term and year 2008 is the base year. In figure 1, the average incomes of the self-employed are higher than the employee in most of the years before 2000. However, the income level of the employee grows steadily over time, largely because they could create more value for their enterprises with enhancement of both personal competence and social network. On the contrary, incomes of the self-employed fluctuate around an approximately constant level over the years. As a result, the average incomes of the employee become higher since 2001. Figure 2 indicates the self-employed have larger risk on their incomes 


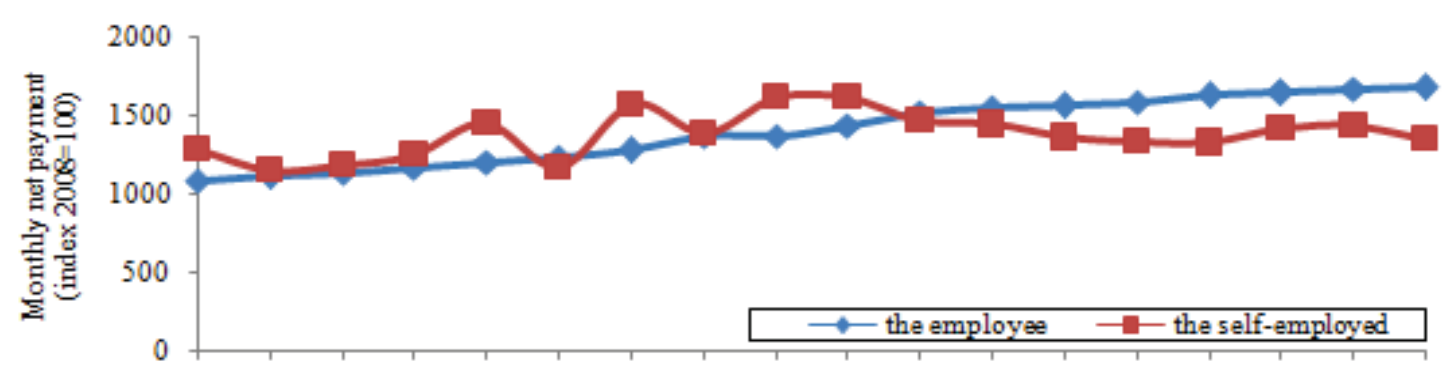

199119921993199419951996199719981999200020012002200320042005200620072008

Figure 1. Comparison of average income between the self-employed and the employee

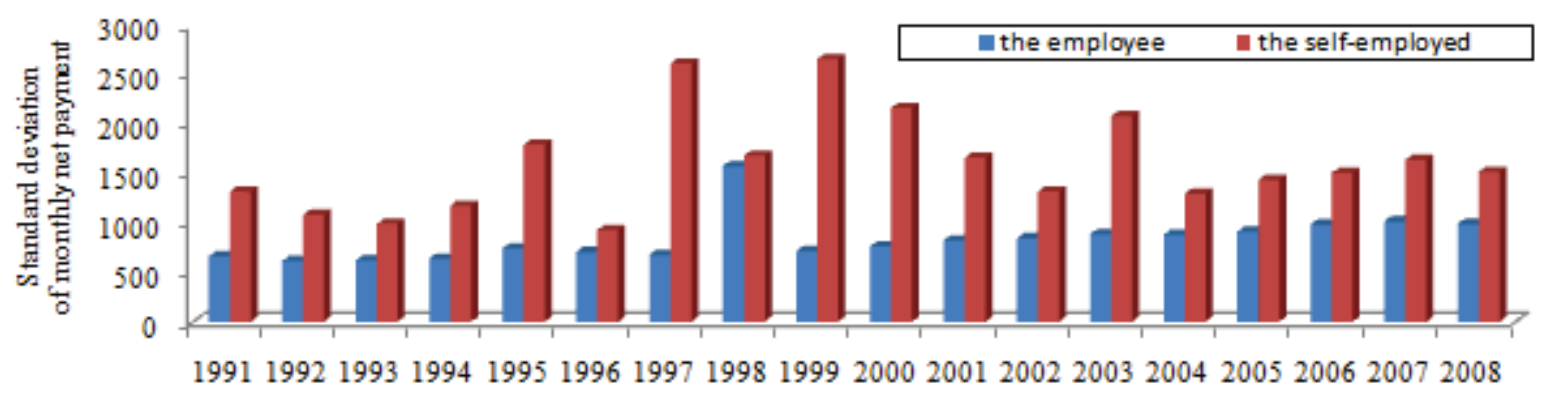

Figure 2. Comparison of income uncertainty between the self-employed and the employee

than the employee, since they undertake the market uncertainty and possibility of failure.

We use subjective well-being and objective health condition to measure the psychological and physical health status respectively. Subjective well-being of the two groups is rated on scale of 0 to 12 by using 12 -item General Health Questionnaire, which is made of questions like "Have you recently felt capable of making decisions about things", "Have you recently felt constantly under strain", etc [15]. It is noted higher score on this variable means worse subjective well-being. Figure 3 reveals the self-employed are better with respect to subjective health status than the employee. In general, the self-employed have the chance to make decisions about their own businesses and confront interesting challenges themselves. It makes the self-employed easier to have the felling of achievement and enjoy their daily life. In contrast, the employee are subject to subordinate employee position, where they have to report to their supervisors and lack opportunity to make decision, and thus are harder to experience subjective happiness.

Objective health condition measures if the subjects have diseases, such as blood pressure, diabetes and migraine, across 18 years. In figure 4, the illness rate of the self-employed is higher than that of the employee in most of the 18 years, and it could be attributed to the work characteristics of the two sectors. It is generally supposed the self-employment is associated with longer working hours and greater job stress. Therefore, the self-employed are inclined to be less healthy. On the other hand, the employee have standard working hours and thus, have more time to take exercise and take care of their own health.

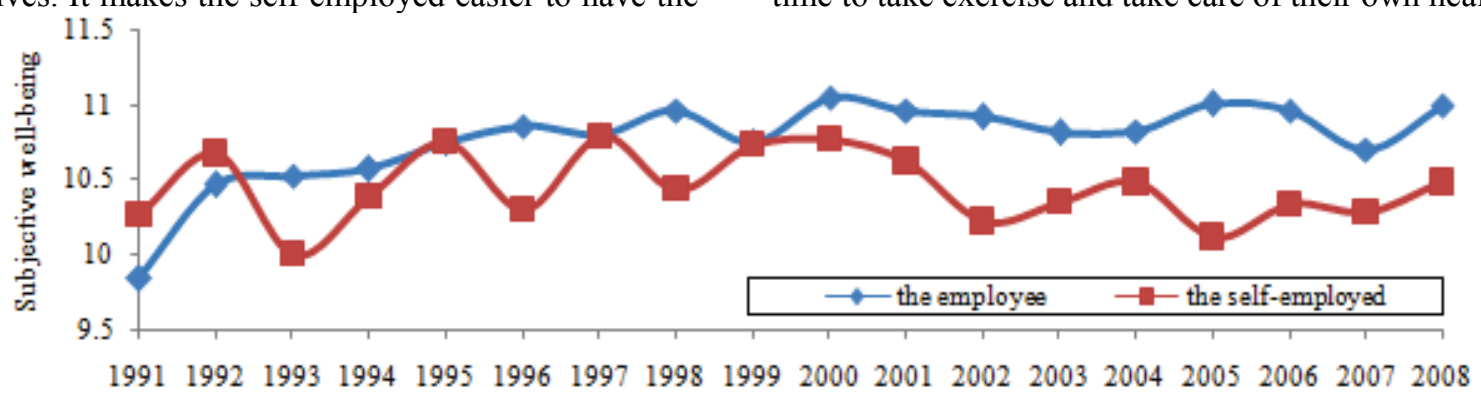

Figure 3. Comparison of subjective well-being between the self-employed and the employee 


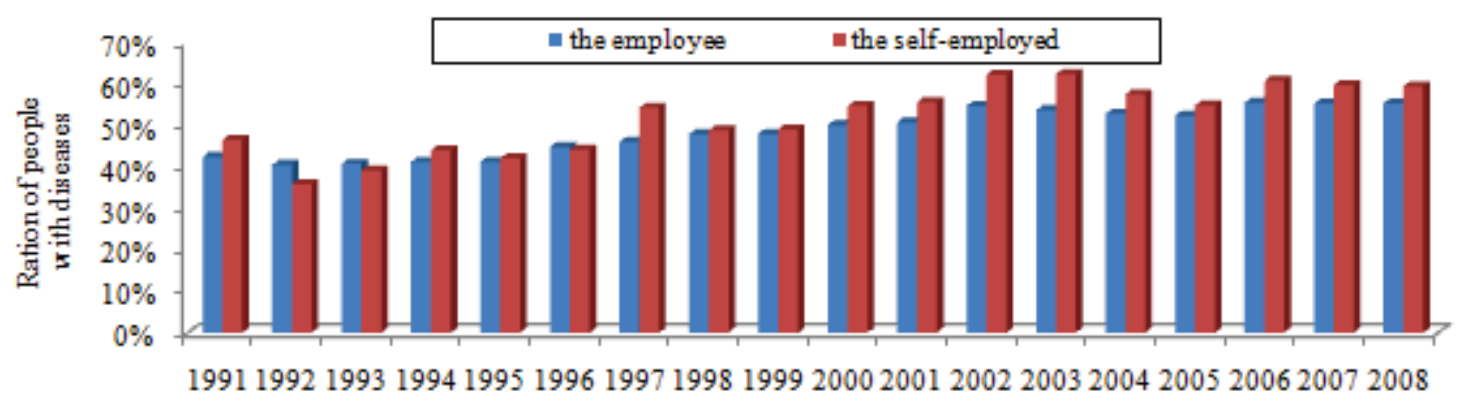

Figure 4. Comparison of objective health condition between the self-employed and the employee

\section{The Statistical Model}

We use the GEE approach to model our longitudinal data sample, and the best model is shown in table 1. Personal employment status is used as dependent variable. The dependent variables include income variable, healthrelated variables, and other variables controlling for the differences between the self-employed and employee in other aspects. The QIC value of this model is -52510 . In addition, the p-values of all the estimates are less than 0.1 . Therefore, all the variables in the model are significant and have the explanatory power for the employment status given $90 \%$ confidence.

Table 1. The GEE model

\begin{tabular}{|c|c|c|}
\hline Variables & Estimates & $\begin{array}{c}\text { Standard } \\
\text { errors }\end{array}$ \\
\hline Intercept & $-4.880 \times 10^{-2 *}$ & $2.844 \times 10^{-2}$ \\
\hline Monthly net payment & $-2.172 \times 10^{-5 * * *}$ & $5.060 \times 10^{-6}$ \\
\hline Subjective well-being & $-0.991 \times 10^{-3 * *}$ & $4.551 \times 10^{-4}$ \\
\hline Objective health condition & $1.631 \times 10^{-2 * * *}$ & $4.496 \times 10^{-3}$ \\
\hline Number of visits to hospital & $-1.659 \times 10^{-2 * * *}$ & $2.220 \times 10^{-3}$ \\
\hline Age & $5.258 \times 10^{-3 * * *}$ & $2.371 \times 10^{-4}$ \\
\hline Number of children in household & $1.038 \times 10^{-2 * * *}$ & $2.330 \times 10^{-3}$ \\
\hline \multicolumn{3}{|l|}{ House ownership dummies } \\
\hline Owned outright & $7.346 \times 10^{-2 * * *}$ & $1.910 \times 10^{-2}$ \\
\hline Buying mortgage or loan & $3.554 \times 10^{-2 *}$ & $1.815 \times 10^{-2}$ \\
\hline Rented & $3.805 \times 10^{-2 * *}$ & $1.929 \times 10^{-2}$ \\
\hline \multicolumn{3}{|l|}{ Occupation dummies } \\
\hline Senior officials and managers & $9.322 \times 10^{-2 * * *}$ & $8.507 \times 10^{-3}$ \\
\hline Professionals & $7.591 \times 10^{-2 * * *}$ & $8.164 \times 10^{-3}$ \\
\hline $\begin{array}{l}\text { Technicians and associate profes- } \\
\text { sionals }\end{array}$ & $3.611 \times 10^{-2 * * *}$ & $7.350 \times 10^{-3}$ \\
\hline Clerks & $-6.348 \times 10^{-2 * * *}$ & $5.018 \times 10^{-3}$ \\
\hline $\begin{array}{l}\text { Skilled agricultural and fishery } \\
\text { workers }\end{array}$ & $4.191 \times 10^{-1 * * *}$ & $2.868 \times 10^{-2}$ \\
\hline Craft and related trades workers & $1.292 \times 10^{-1} * * *$ & $8.769 \times 10^{-3}$ \\
\hline \multicolumn{3}{|l|}{ Race dummies } \\
\hline White & $-6.803 \times 10^{-2 * * *}$ & $1.669 \times 10^{-2}$ \\
\hline Black & $1.446 \times 10^{-1 * * *}$ & $4.290 \times 10^{-2}$ \\
\hline Chinese & $6.509 \times 10^{-1 * * *}$ & $6.952 \times 10^{-2}$ \\
\hline
\end{tabular}

a. *p-value $<0.10 ; *$ p-value $<0.05 ; * * *$ p-value $<0.01$.
The coefficient of monthly net payment is negative and small. It means the self-employed are weakly correlated to lower income over the 18 years. This result is just the opposite to the previous researches, which consider the higher income is among the most attractive factors of the entrepreneurship. However, these studies are always based on cross-sectional data set. As figure 1 shows, incomes of the employee rise steadily over the years due to enhancement of personal capability and probable promotion, while those of the self-employed fluctuate almost around a constant level. This time trend makes the employee received greater financial return than the self-employed in the long term, even though the incomes difference is very small.

For respondents' health statuses, the final model incorporates 3 variables. The coefficient of subjective well-being is negative. Consider low score on this variable means high well-being, it implies the self-employed are in association with better subjective well-being. This result is consistent with our descriptive statistics before. Compared with the employee, the self-employed have high degree of independence and devote themselves into the jobs they have enthusiasm in. It would lead to better psychological experience in daily life and hence, better subjective well-being. In contrast, the employee have fixed work scope and need to be evaluated by the supervisor on their performance periodically.

The coefficient of objective health condition is positive, which reflects the employee are generally in better shape physically than the self-employed. Previous research always find the entrepreneurship a more demanding status, since individuals have to put a lot of effort and time into their own businesses, so as to cope with the market uncertainty and pressure of failure. In the long term, it is more likely that the self-employed would experience a decline in physical health.

However, the self-employed are associated with less visits to hospital in general despite their poorer health conditions. We could see from this result that, the self-employed are always willing to make the best of 
time to promote their own businesses, so they do not want to spend their time on seeing the doctors as long as they are able to bear the illness. For the employee, they could visit the hospital in spare time or take a sick leave.

\section{Discussion and Policy Implications}

Programmes and policies to promote entrepreneurship are very common in developed countries like Britain. They take on various forms to support people with willing to become self-employed, including skill training, access to financial support and mentor support, the provision of work place, etc. In this section, we provide some valuable policy suggestions in promoting entrepreneurship, based on results of the present study.

In the long run, the employee tend to get promoted and obtain a stable growth in earnings, while the actual incomes of the self-employed keep almost unchanged. Besides, the self-employed have higher uncertainty in earnings than the employee. Therefore, individuals lack sufficient economic incentives to set up their own businesses.

To resolve this problem, some adjustments to taxation system could be conducted, so as to improve the relative net incomes of the self-employed to the employee. Specifically, the differences in the tax bases between the entrepreneurship and paid-employment could be employed for this purpose [16]. For instance, tax policies can be established to allow the self-employed to deduct extra cost and expense from taxable income. In addition, early research also supported that, higher marginal tax rates are in association with higher rates of entrepreneurship [17]. Apart from legitimate differential in tax bases between the two employment options, the self-employed have more opportunities to misreport their taxable income. And these differences could be amplified with increase in marginal tax rate.

In terms of heath, our study shows the objective health conditions of the self-employed are averagely worse than the employee. However, the self-employed visit the hospital less than the employee. In addition to full schedule of the self-employed, this observation also results from the fact that, companies always provide allowance for the medical expenses of their employees.

Therefore, programmes aimed at improving the health condition and providing better medical insurance for the self-employed should be initiated. First, the communities could run health knowledge lectures and training classes for registered self-employed, to promote their health consciousness. And it is also an effective way to provide well-appointed playground at favorable price or for free, in order to inspire their willing to take exercises. Second, the government could provide the self-employed with a more comprehensive health service system, which in- cludes but is not limited to: regular physical examination, extra allowance for medical expenses, and an exclusive green channel to see the doctor. These measures are expected to stimulate the self-employed to visit the hospital when they really fall sick.

\section{Conclusion}

In summary, our study sheds light on the long-term relationship between income, health and entrepreneurship. Distinct from previous research based on cross-sectional data, the self-employed do not have greater returns from work than the employee, and the association between employment status and income is very small. In terms of health, the self-employed generally experience better subjective well-being than the employee, but are in worse shape with respect to objective health condition. The reason is that, the self-employed are free from the subordinate employee position and more likely to experience the feeling of achievement; however, the entrepreneurship requires individuals to put more effort and time into the businesses, which would result in a decline in physical health in the long run. To stimulate the entrepreneurship, suggestions about improving the relative incomes and health conditions for the self-employed are made for the policymakers' references.

For future research, we find it promising to explore the entrepreneurship in China based on our methods and results, since the Chinese government begins to attach more importance to the self-employment. It is expected to provide some insights to the Chinese policymakers in promoting entrepreneurship.

\section{REFERENCES}

[1] D. Jayawarna, J. Rouse and J. Kitching, "Entrepreneur Motivations and Life Course," International Small Business Journal, published online before print June 29, 2011. http://dx.doi.org/10.1177/0266242611401444

[2] M. Jamal, "Job Stress, Satisfaction, and Mental Health: An Empirical Examination of Self-employed and Non-self-employed Canadians," Journal of Small Business Management, Vol. 35, No. 4, 1997, pp. 18-57. http://dx.doi.org/10.1002/jae.3950010107

[3] H. Rees and A. Shah, "An Empirical Analysis of Self-Employment in the UK," Journal of Applied Econometrics, Vol. 1, No. 1, 1986, pp. 95-108. http://dx.doi.org/10.1002/jae.3950010107

[4] I. Bernhardt, "Comparative Advantage in Self-employment and Paid Work," Canadian Journal of Economics, Vol. 27, No. 2, 1994, pp. 273-289. http://dx.doi.org/10.2307/135747

[5] M. P. Taylor, "Earnings, Independence or Unemployment: Why Become Self-employed," Oxford Bulletin of Economics and Statistics, Vol. 58, No. 2, 1996, pp. 253-265. http://dx.doi.org/10.1111/j.1468-0084.1996.mp 58002003.x 
[6] D. G. Blanchflower and C. Shadforth, "Entrepreneurship in the UK," Foundations and Trends in Entrepreneurship, Vol. 3, No. 4, 2007, pp. 257-264. http://dx.doi.org/10.1561/0300000017

[7] M. Jamal, "Burnout and Self Employment: A Cross-Cultural Empirical Study," Stress and Health, Vol. 23, No. 4, 2007, pp. 249-256. http://dx.doi.org/10.1002/smi.1144

[8] N. Lewin-Epstein and E. Yuchtman-Yaar, "Health Risks of Self-Employment," Work and Occupations, Vol. 18, No. 3, 1991, pp. 291-312. http://dx.doi.org/10.1177/073088849101800300 $\underline{3}$

[9] R. A. Parslow, A. F. Jorm, H. Christensen, B. Rodgers, L. Strazdins and R. M. D'Souza, "The Associations between Work Stress and Mental Health: A Comparison of Organizationally Employed and Self-employed Workers," Work \& Stress, Vol. 18, No. 3, 2004, pp. 231-244. http://dx.doi.org/10.1080/147497304123313186 $\underline{49}$

[10] D. J. Prottas and C. A. Thompson, "Stress, Satisfaction, and the Work-family Interface: A Comparison of Self-employed Business Owners, Independents, and Organizational Employees," Journal of Occupational Health Psychology, Vol. 11, No. 4, 2006, pp. 366-378. http://dx.doi.org/10.1037/1076-8998.11.4.366

[11] D. Jayawarna, J. Rouse and A. Macpherson, "Modeling
Pathways to Entrepreneurship: A Life Course Perspective," Working Paper, Manchester Metropolitan University Business School, 2011.

[12] J. Scheffer, "Dealing with Missing Data," Research Letters in the Information and Mathematical Sciences, Vol. 3, No. 1, 2002, pp. 153-160.

[13] S. L. Zeger and K. Y. Liang, "Longitudinal Data Analysis for Discrete and Continuous Outcomes," Biometrics, Vol. 42, No. 1, 1986, pp. 121-130. http://dx.doi.org/10.2307/2531248

[14] W. Pan, "Akaike's Information Criterion in Generalized Estimating Equations," Biometrics, Vol. 57, No. 1, 2001, pp.

120-125. http://dx.doi.org/10.1111/j.0006-341X.2001.001 20.x

[15] D. Goldberg and P. Williams, "A user's guide to the General Health Questionnaire," 1st Edition, UK: NFER-Nelson, Windsor, 1988.

[16] J. E. Long, "Income Taxation and the Allocation of Market Labor," Journal of Labor Research, Vol. 3, No. 3, 1982 , 259-276. http://dx.doi.org/10.1007/BF02685189

[17] D. M. Blau, "A Time-Series Analysis of Self-Employment in the United States," Journal of Political Economy, Vol. 95, No. 3, 1987, pp. 445-467. http://dx.doi.org/10.1086/261466 